\title{
Flow Behavior of Sterically Stabilized Suspensions
}

\author{
by \\ Yasufumi Otsubo and Koichiro Watanabe \\ Department of Image Science and Technology, Faculty of Engineering, \\ Chiba University, 1-33, Yayoi-cho, Chiba-shi 260
}

Flow behavior of sterically stabilized suspensions was studied by the use of silica suspensions in polyacrylamide (PAAm) solutions. Adsorption of PAAm on the silica particles causes depletion of the polymer concentration in the liquid phase and volume augmentation of the dispersed phase. The former effect is predominant at low particle concentrations and hence the zero shear viscosity of suspension becomes lower than that of the medium. At intermediate concentrations, pseudoplastic behavior appears at shear rates corresponding to Newtonian range of the medium. At high concentrations, suspensions exhibit pseudoplastic behavior, followed by dilatancy progressing to viscosity instability. The viscosity instability may be attributed to the abrupt break up of ordered arrays of particles discovered by Hoffman for systems including particles by mor ethan 50\%. The total effective volume of our dispersed phase is likely to be increased to about $50 \%$. The flow behavior is discussed in relation to a potential energy diagram which combines van der Waals attraction and steric repulsion due to the interaction of adsorbed polymer layers.

\section{立体安定化されたサスペンションの流動挙動}

\author{
大 坪 泰 文・渡 辺 鋼市郎*
}

（原稿受理：1985年12月11日）

\section{1. 緒}

粒子表面に吸着した高分子の立体障害的相互作用により，サス ペンションが分散安定化される現象を立体安定化という。高分子 による立体安定化機構を説明しょうとする理論はいくつか提出さ れているが，大別すると統計力学的立場から導かれる理論之，高 分子溶液論的立場から導かれる理論との二つになる1)。吸着高分 子と溶媒との相互作用を考虑した後者の理論によると，立体安定 化効果に最む大きな影響を及ぼす熱力学的因子は，高分子と溶媒 との相互作用パラメーター $\chi_{1}$ であり，良溶媒を用いた場合，サ スペンションは立体安定化され，貧溶媒を用いたときは凝集する ことが知られている.

立体安定化されたサスペンションは，粒子間相互作用のないサ スペンションのモデルとして最適であり, 粒子濃度と見掛け粘度

\footnotetext{
* 千葉大学工学部画像応用工学科 $\overline{\mathbf{T}} 260$ 千葉市弥生町 $1-33$
}

との関係についてラテックスを用いてさかんに研究が行われてい る2) 7). 乙のようなサスペンションの流動挙動は, 微視的には粒 子に働く流体力学的せん断力と, ブラウン運動とのバランスによ り支配されるので, 流動曲線は式(1)で定義される無次元せん断速 度 $\Gamma$ の関数で表される ${ }^{8)}$.

$$
\Gamma=\frac{\eta_{0} a^{3} \dot{\gamma}}{k T}
$$

ここで， $n_{0}$ は分散媒（二ュートン流体）の粘度*1，a は粒子半径, $\dot{\gamma}$ はせん断速度, $k$ は Boltzmann 定数, $T$ は絶対温度である. 多 くのラテックスサスペンションにおいて，粒子濃度が一定ならば， サスペンションの見掛け粘度 $\eta_{\mathrm{a}}$ を $\Gamma$ 対してプロットすると， 分散媒粘度や粒径によらず一本の曲線になることが確かめられて (る ${ }^{9), 10)}$. しかし, 粒子表面への高分子の吸着挙動とレオロジー

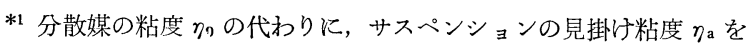
用いることもあるが，この場合は還元せん断応力と呼ばれている。 
Table I. Typical properties of Aerosil 130

$\begin{array}{lc}\text { Particle diameter } & 20 \mathrm{~nm} \\ \text { Surface area } & 130 \pm 25 \mathrm{~m}^{2} / \mathrm{g} \\ \text { Specific gravity } & 2.1 \\ \text { Silanol coverage } & 3 \mathrm{SiOH} / \mathrm{nm}^{2}\end{array}$

挙動とを関連づけた系統的研究は，まだ少ないようである．本研 究では, 超微粉シリカを用いてサスペンションの流動挙動に及ぼ す粒子表面への高分子吸着の影響について検討した。

\section{2. 実}

\section{験}

試料は, ポリアクリルアミド (PAAm) の $0.5 \mathrm{wt} \%$ グリセリ ン溶液を分散媒とするシリカサスペンションである. PAAm と しては, Dow Chemical 社製 Separan NP10 $\left(M_{\mathrm{w}} \doteqdot 2 \times 10^{6}\right)$, Scientific Polymer Product 社製の標準 PAAm $\left(M_{\mathrm{w}} \div 5 \times 10^{6}\right)$, 日東化学工業製ポリダイヤ PDA-1041 $\left(M_{\mathrm{w}} \div 1 \times 10^{7}\right)$ の三種類 の市販品を用いた. シリカとしては, Degussa 社製 Aerosil 130 を用いた。 その主な性状を Table I に示す. サスペンションは調 製してから一週間静置後, 充分脱気を行って測定に供した。粒子 濃度は 1 〜 $15 \mathrm{wt} \%$ である. なお，乙こで用いたすべてのサスぺ ンションが透明であった。

レオロジー測定には二重円筒型回転粘度計を用い, $9.5 \times 10^{-3} \sim$ $1.9 \times 10^{1} \mathrm{~s}^{-1}$ のせん断速度範囲で見掛け粘度 $\eta_{\mathrm{a}}$ を測定した。 ての 粘度計に扔いては, 内筒に㗢くせん断応力はそれをつり下げてい るトーションワイャーの秃じれして検出される. 测定温度はす べて $30^{\circ} \mathrm{C}$ である.

\section{3. 結果 と考 察}

Fig. 1 は, 分子量500万の PAAm のグリセリン溶液を用いて 調製したサスペンションの流動挙動である. $5 \mathrm{wt} \%$ 以下の低粒子 濃度において, 見掛け粘度は低せん断速度で一定值となりニュー トン流動を示す. しかし, 通常のサスペンションと異なり, ての シリカサスペンションにおいてはゼロせん断粘度の值が分散媒の 值より小さくなるという特異な挙動を示す。粒子濃度が $7 \mathrm{wt} \%$ では, 分散媒がニュートン流動を示す低せん断速度域です擬塑性 流動を示すようになる.さらに, 粒子濃度が増加し $10 \mathrm{wt} \%$ 以上 になる之，低せん断速度域で擬塑性流動を示すととすに，高せん 断速度域でダイラタント流動が観測されるようになる. 粒子濃度 が $5 \mathrm{wt} \%$ 以上では, 見掛け粘度は測定せ九断速度全域で粒子濃 度とともに增大する。ところで, 粒子濃度が $13 \mathrm{wt} \%$ のサスペン

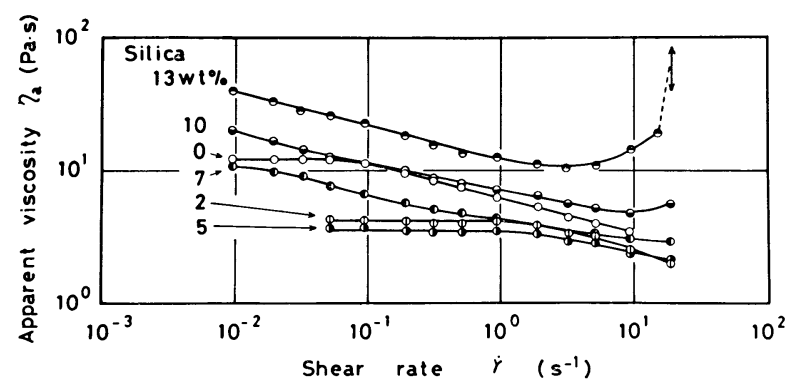

Fig. 1 Shear rate dependence of apparent viscosity for suspensions in a solution of PAAm with $M_{\mathrm{w}}=5 \times 10^{6}$.

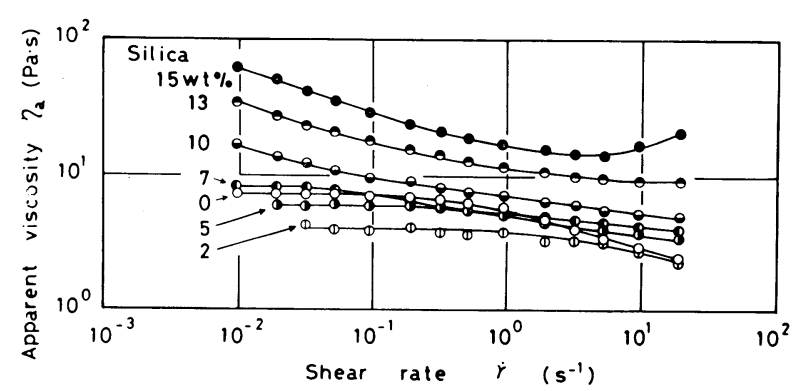

Fig. 2 Shear rate dependence of apparent viscosity for suspensions in a solution of PAAm with $M_{\mathrm{w}}=2 \times 10^{6}$.

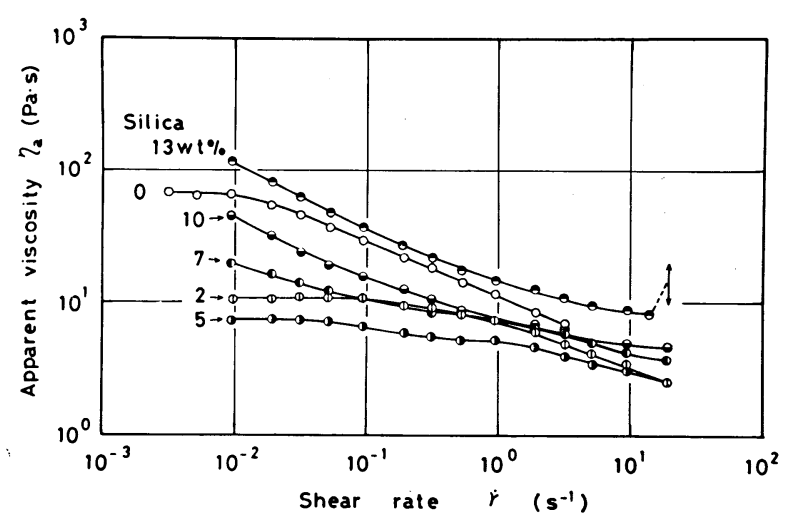

Fig. 3 Shear rate dependence of apparent viscosity for suspensions in a solution of PAAm with $M_{\mathrm{w}}=1 \times 10^{7}$.

ションにおいては，せん断速度が $16 \mathrm{~s}^{-1}$ 以上で突然に内筒が大き く振動する粘度不安定現象が現れた。この領域では, 一定回転数 で外筒を回転しているにあかかわらず粘度計の読みが不安定にな り，定常的な見掛け粘度の值が得られなかった．Fig. 1 亿おける 矢印は，乙のときの振動の範囲を示すすのである．乙こで現れた 粘度不安定挙動は, 測定の順序によらず可逆であり, 低せん断速 度側から測定してあ高せん断速度側から測定しても， $\dot{\gamma}=16 \mathrm{~s}^{-1}$ が 臨界せん断速度となる。

分子量の異なる PAAm のグリセリン溶液を用いて調製したサ スペンションについても, 同様の実験を行った. 分子量 200 万の PAAm に対する結果を Fig. 2 飞, 分子量1,000万の PAAm に 対する結果を Fig. 3 亿示す. おおよその挙動は Fig. 1 と同じで あるが, 分子量 200 万の場合は粒子濃度を $15 \mathrm{wt} \%$ にまで増加し ても, 粘度不安定現象は現れない, 分子量 1,000 万の PAAm 溶 液を分散媒とするサスペンションにおいては，粒子濃度が $13 \mathrm{wt}$ \%になってあダイラタント領域は現れないが，擬塑性領域から粘 度不安定領域へと突然に転移する。特にてのサスペンションにお いては, シリカ分散による粘度減少効果が著しく， $5 \mathrm{wt} \%$ サス ペンションのゼロせん断粘度は分散媒の $1 / 10$ にまで減少してい る. PAAm の分子量が大きいと, 低粒子濃度です PAAm の分 子量が小さい場合の高粒子濃度に対応する流動挙動が現れるもの と推察される.

以上の流動挙動は, シリカ粒子表面への PAAm の吸着挙動之 密接に関係している。まず, 低粒子濃度においてサスペンション のゼロせん断粘度が高分子溶液より低くなるのは, 粒子表面に多 
量の高分子が吸着して, 溶液相における濃度が下がるととによる あのである．分子量 200 万の PAAm を用いた吸着実験 ${ }^{11), 12)} に よ$ ると, シリカに対する 飽和吸着量は約 $1.6 \mathrm{mg} \cdot \mathrm{m}^{-2}$ であり, 吸 着層中における高分子濃度は $0.178 \mathrm{~g} \cdot \mathrm{cm}^{-3}$ であった. 粒子表面 飞高分子が吸着されると，吸着高分子屯固体のようにふるまうの で分散相の体積濃度が増加する. しかし, 分散相の体積増加に起 因する粘度増加より, 吸着による溶液相の粘度減少の効果が大き いため，全体としてサスペンションの粘度が減少するあのである． そこで，分子量500万の PAAm 溶液を分散媒とする $2 \mathrm{wt} \%$ シ リカサスペンションについて, 吸着層中の PAAm 濃度を 0.178 $\mathrm{g} \cdot \mathrm{cm}^{-3}$ として吸着層の厚さを概算した。 最初に吸着層の厚さ $h$ を仮定すると, 分散相の体積分率 $\phi$ 之溶液相中の高分子濃度が定 まる. 高分子溶液におけるゼ口せん断粘度と濃度との関係は実測 できるので，乙のときの溶液相粘度 $\eta_{0}$ が求まることになる．そ こで, 次の Guth-Gold の式 ${ }^{13)}$

$$
\frac{\eta}{\eta_{0}}=1+2.5 \phi+14.1 \phi^{2}
$$

が適用できるとすると, サスペンションのゼロせん断粘度 クと溶 液相中の高分子濃度との関係を予測することができる. Fig. 4 は これをまとめたものであり, 実線とプロットが高分子溶液におけ るゼロせん断粘度と濃度との関係の実測值, 点線が $2 \mathrm{wt} \%$ サス ペンションに拈けるゼロせん断粘度と, 溶液相中の高分子濃度と の関係の予測である. 実際の $2 \mathrm{wt} \%$ サスペンションにおけるゼ 口せん断粘度の值は $4.8 \mathrm{~Pa} \cdot \mathrm{s}$ であり, てれから得られた吸着層 の厚さは $9 \mathrm{~nm}$ であった。 一般に知られている高分子吸着層の厚 さと同程度であり ${ }^{14) \sim 16)}$, シリカ粒子は粒子自身の半径とほぼ同 じ厚さの吸着層で覆われていることがわかる.

吸着高分子に覆われた粒子の全粒子間ポテンシャル $V_{\mathrm{T}}$ は, 静 電的反発ポテンシャル $V_{\mathrm{el}}$, 立体反発ポテンシャル $V_{\mathrm{R}}$ および London-van der Waals 引力ポテンシャル $V_{\mathrm{A}}$ との和で表される.

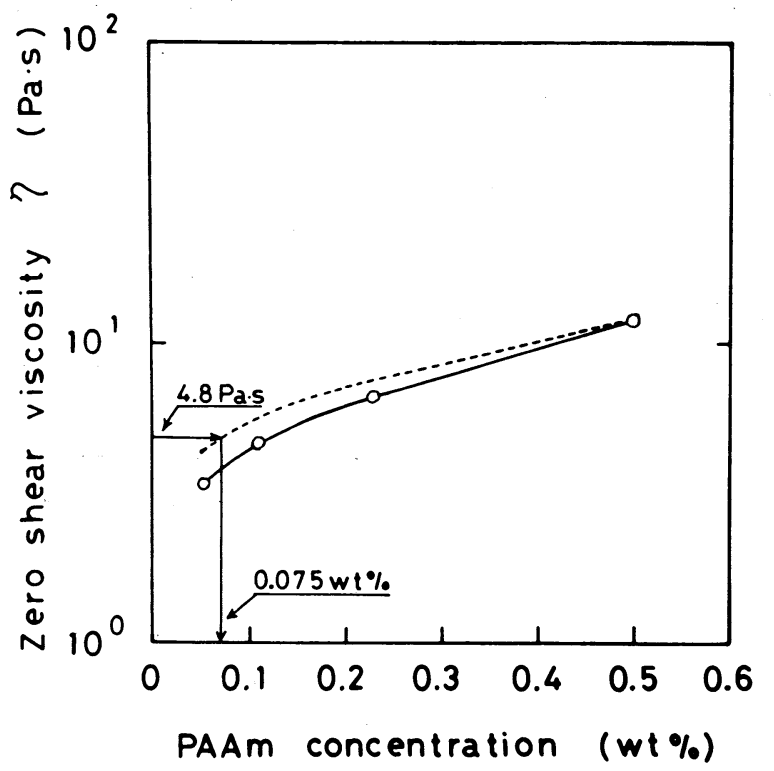

Fig. 4 Calculation procedure of adsorbed layer thickness. Circles : zero shear viscosity of polymer solution, Dashed line : prediction for zero shear viscosity of $2 \mathrm{wt} \%$ suspension as a function of polymer concentration in the liquid phase.
一般に, 非水系の電気二重層はかなり拡がっており, 粒子濃度が 高いときはその作用は非常に小さくなることが知られているので, ここでは $V_{\mathrm{el}}$ は無視できるあのとした，そして， $V_{\mathrm{R}}$ をOttewillWalker の式 ${ }^{17)}, V_{\mathrm{A}}$ をVold の式 ${ }^{18)}$ により計算した. $V_{\mathrm{R}}$ の計算 に際しては, 浸透圧効果と容積制限効果の両者を考慮する必要が あるが, 吸着高分子層が触れ始めた段階では, 浸透圧効果が支配 的となるので次式を用いた。

$$
\begin{aligned}
V_{\mathrm{R}}= & \frac{4 \pi k T c^{2}}{3 V_{1} \rho_{2}^{2}}\left(\frac{1}{2}-\chi_{1}\right)\left(h-\frac{d}{2}\right)^{2}\left(3 a+2 h+\frac{d}{2}\right) \\
V_{\mathrm{A}}= & -\frac{1}{12}\left\{\left(\sqrt{A_{22}}-\sqrt{A_{33}}\right)^{2} \frac{a+h}{d}+\left(\sqrt{A_{22}}-\sqrt{A_{11}}\right)^{2} \frac{a}{d+2 h}\right. \\
& +4 a\left(\sqrt{A_{22}}-\sqrt{A_{33}}\right)\left(\sqrt{A_{33}}-\sqrt{A_{11}}\right) \frac{a+h}{(d+h)(2 a+h)}
\end{aligned}
$$

ここで， $a$ はシリカ粒子半径, $d$ はシリカ粒子の表面間距離, $c$ は吸着層中の高分子濃度, $\rho_{2}$ は高分子の密度, $V_{1}$ は溶媒の分子 体積である.さらに， $A_{\mathrm{ij}}$ は物質 $\mathrm{i}$ と物質 $\mathrm{j}$ との間の相互作用に 関する Hamaker 定数であり，乙こではシリカを 1 ，グリセリン を 2 , PAAmを 3 によってある. 式(3)より， $\chi_{1}<0.5$ である良溶 媒を用いたとき， $V_{\mathrm{R}}$ は正となり粒子間には反発力が働くが， $\chi_{1}$ $>0.5$ である貧溶媒を用いたとき， $V_{\mathrm{R}}$ は負となり粒子間には引力 が働くことがわかる. 本実験では, 粘度データより $\chi_{1} を 0.491$ と した. また, Hamaker 定数は文献値より ${ }^{19), 20)}, A_{11}=15 \times 10^{-20} \mathrm{~J}$, $A_{22}=7.4 \times 10^{-20} \mathrm{~J}, A_{33}=6.5 \times 10^{-20} \mathrm{~J}$ とした. 乙れらの值を代入し て求めた $V_{\mathrm{R}}, V_{\mathrm{A}}$ および $V_{\mathrm{T}}$ 曲線を Fig. 5 亿示す. 一般に全粒 子間ポテンシャル曲線には, その值に大小の差はあっても極小が 現れる。乙の負の值が大きいとき, つまり谷が深いとき粒子は凝 集し, 浅いときは粒子のブラウン運動のエネルギーにより打ち勝 ち分散状態を保つことができる. そして, その臨界值は $-5 k T$ 程 度であると言われているが, 本研究で得られた谷の深さは -0.15 $k T$ であった．また，粒子の接近に対して大きな反発力が働くて とから, サスペンションは凝集に対して極めて安定であるてとが

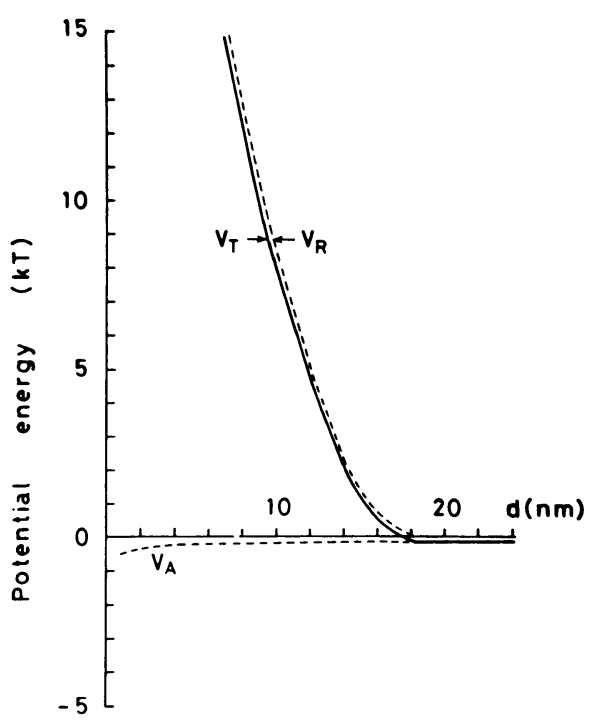

Fig. 5 Potential energy diagram for two approaching particles. $V_{\mathrm{A}}$ : London-van der Waals attraction potential, $V_{\mathrm{R}}$ : steric repulsion potential, $V_{\mathrm{T}}$ : total potential. 
コロイド化学的に理解できる.

シリカ濃度が低いと, 低せん断速度域でニュートン流動が観測 されるが, 粒子濃度が増加すると, 乙の領域です擬塑性流動を示 すようになる，高分子溶液を分散媒とする多くのサスペンション は, 高分子溶液がニュートン流動を示す低せん断速度域で擬塑性 流動を示すととが知られており，乙れは粒子の凝集に起因するす

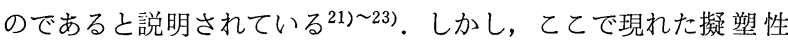
流動は, 粒子間の流体力学的相互作用によるあのと考えられる. ほとんど粒子間引力のないサスペンションにおいても, 粒子濃度 が 20〜30 vol\%になる ， 流体力学的相互作用により顕著な擬塑 性流動の出現が予想されることから, シリカ濃度が低くて屯高分 子吸着により分散相濃度が増加して, 粒子間の衝突頻度が上がり, このような挙動が現れたあのと推察される．たとえば，シリカ濃 度が $7 \mathrm{wt} \%$ (約 $4 \mathrm{vol} \%$ )であ吸着層の厚さを $9 \mathrm{~nm}$ とすると, 分散相の体積濃度は約 $28 \mathrm{vol} \%$ にまで増加するととになる．前述 したように, 立体安定化されたサスペンションの流動挙動は, 無 次元せん断速度と見掛け粘度との関係で整理することができるが， この場合，粒子径と分散媒粘度がわかっていなければならない． 本研究で用いたサスペンションにおいては, 高分子吸着による粒 子径の増大と，溶液相粘度の低下が起てっているので，すべての 系についてそれらを求めることは容易ではない，また，先ほど求 めた高分子吸着層の厚さ $9 \mathrm{~nm}$ は, 飽和吸着に対する值であり, 粒子濃度が $5 \mathrm{wt} \%$ 以上になると，飽和吸着にまで至っていない と考えられるので，乙の值を適用することあできない，一般に， 高分子の吸着量之吸着層の厚さとの関係を正確に求めることは難 しく, 特に超微粒子の表面に吸着した高分子の厚さを求めるには, かなりの困難を伴うことが予想される，そこで，乙こでは次の三 種類のサスペンションの流動挙動から, 吸着高分子の厚さと分子 量との関係について推察することにした。すなわち，Fig. 1 の $10 \mathrm{wt} \%$ サスペンション, Fig. 2 の $10 \mathrm{wt} \%$ サスペンションお よびFig. 3 の 7 wt\%サスペンションであり，乙れらを一つにま とめると Fig. 6 のようになる。見掛け粘度のせん断速度依存性 が一本の曲線で表されるととから，乙れらのサスペンションの流 動挙動にはほとんど差はなく, 分散相の体積濃度は高分子吸着に よりほぼ同程度にまで増加していると考えられる，また，サスぺ ンション中においては, 大部分の高分子がシリカ表面に吸着して

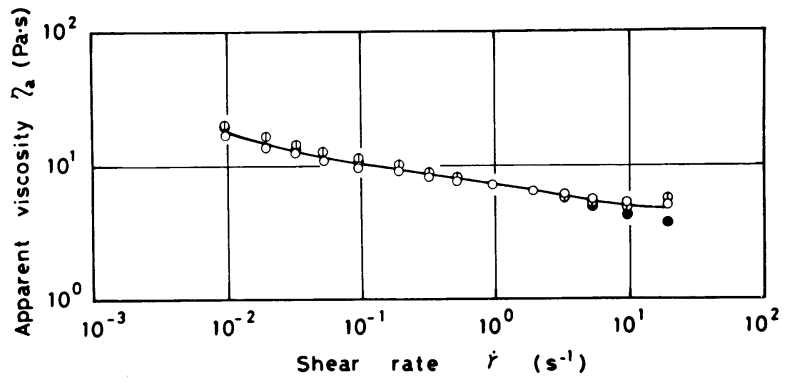

Fig. 6 Shear rate dependence of apparent viscosity for three different suspensions. Unfilled circles : $10 \mathrm{wt} \%$ suspension in a solution of PAAm with $M_{\mathrm{w}}=2 \times 10^{6}$, Circles with slot : $10 \mathrm{wt} \%$ suspension in a solution of PAAm with $M_{\mathrm{w}}=$ $5 \times 10^{6}$, Filled circles : $7 \mathrm{wt} \%$ suspension in a solution of PAAm with $M_{\mathrm{w}}=1 \times 10^{7}$.

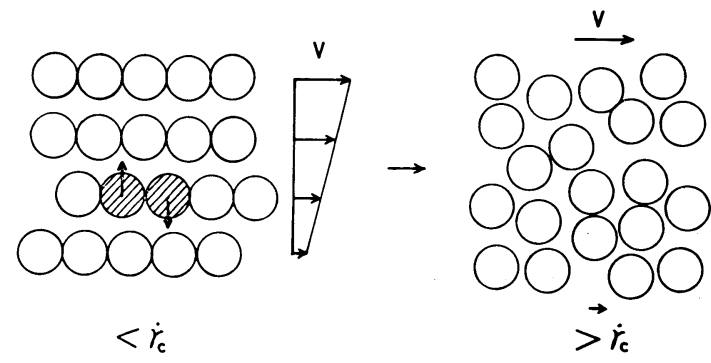

Fig. 7 Structural change at the viscosity discontinuity point.

いるあのと思われる，乙のような挙動は，わずかではあるが，分 子量が大きいほど吸着層が厚くなることを示唆するものであろう。 さて，さらに粒子濃度を增加させると粘度不安定現象が現れる が，乙れは Hoffman が報告している粘度ジャンプと同じ現象か と思われる ${ }^{24), 25)}$. 彼は, 50 vol\%以上の高濃度ラテックスの流動 挙動を測定すると, ダイラタント流動が現れるせん断速度よりさ らに高いせん渐速度において，粘度が不連続に増大することを見 いだし，乙れが分散粒子の二次元的規則構造の破壊によるむので あるととを示した. その機構を模式的に示したのが Fig. 7 である. いま，斜線を施した二つの粒子を一つのダブレットと考えると， せん断下においては矢印で示したような力が働き，ダブレットは その重心を中心にして回転しようとする。しかし，せん断速度が 低いときは，上の層にある粒子または下の層にある粒子との間の 反発力により回転運動が抑えられ, 粒子は層状になって流れる. この層は二次元の六方最密構造をとっている，ところが，せん断 速度が大きくなると, 流体力学的な回転力が大きくなるため, つ いにはこの構造を支えきれなくなり，あるせん断速度で突然に不 規則構造へ之転移する。乙れがレオロジ一的には粘度ジャンプと して観測されるあのであり，Hoffman は光の回折により二次元 規則構造を確認している. 彼が用いたのは, $1 \mu \mathrm{m}$ 程度の粒子で あるが, 本研究で用いたシリカは直径が約 $20 \mathrm{~nm}$ の超微粒子であ るため, 高分子溶液に分散させて屯透明になり, このような光学 的検証は得られなかった。 しかし, 高分子吸着により分散相濃度 がかなり増加していると考えられることから, Hoffman の提唱 した流体力学的機構により粘度不安定現象が現れたものと推察さ れる. また，分子量200万のPAAmを用いて調製したサスペンシ ョンに拈いては，粒子濃度が $15 \mathrm{wt} \%$ にっても粘度不安定現象 は現れないが，分子量が500万以上になると $13 \mathrm{wt} \%$ 万現れる。 これあ分子量が大きいほど吸着層が厚くなるととを示すあのであ ろう. シリカ粒子表面に吸着した高分子層の厚さが， サスペンシ ョンのレオロジー挙動に対して大きな影響を及ぼしているてとが わかった．乙のような $\mathrm{nm}$ オーダーの超微粒子表面へ吸着した高 分子層の厚さを測定する有効な方法が確立されれば，さらに詳し いコロイド化学的検討が可能になると思われる.

\section{4. 結 論}

PAAm のグリセリン溶液を 分散媒とするシリカサスペンショ ンの流動挙動について調べた結果, 次のてとがわかった.

(1) シリカ濃度が $5 \mathrm{wt} \%$ 以下においては，サスペンションは 低せん断速度において二ュートン流動を示し，そのゼロせん断粘 度の值は分散媒より低くなる．乙れは粒子表面に多量の高分子が 
吸着して, 溶液相の高分子濃度が低下することによるり起てるす ので, コロイド化学的に検討した結果, サスペンションは吸着高 分子により立体安定化されていることがわかった。

（2）粒子濃度が 7〜10 wt\% になると，分散媒がニュートン流 動を示す低せん断速度であ, サスペンションは粒子間の流体力学 的相互作用に起因する擬塑性流動を示す. 乙の領域での流動挙動 から, 高分子の分子量が高くなるほどシリカ表面への吸着層が厚 くなることが推察される。

(3) 粒子濃度がさらに高くなると, 高せん断速度域でダイラタ ント流動およびそれに続く粘度不安定挙動が観測されるようにな る. 分散相の体皘濃度が 50 vol\%程度にまで増加していると予想 されることから，ての粘度不安定現象は分散粒子の二次元規則構 造の破壊によるむのと考えられる。

（昭和60年10月10日，第33回レオロジー討論会にて発表）

[付 記]

本研究は, 昭和 59 年度文部省科学研究費の補助によって行われ た。

\section{文献}

1) 例えば, Sato, T., and R. Ruch, "Stabilization of Colloidal Dispersions by Polymer Adsorption", Chap. 3 (1980) Marcel Dekker, New York.

2) Willey, S.J., and C.W. Macosko, J. Rheol., 26, 557 (1982).

3) Russel, W.B., J. Rheol., 24, 287 (1980).

4) Krieger, I.M., and G.N. Choi, "Advances in Rheology (Proc. 9th Int. Congr. Rheol.)”, ed. by B. Mena, A. Garcia-Rejon, and C. Rangel-Nafaile, Vol. 2, p. 641 (1984).

5) Strivens, T.A., J. Colloid Inter face Sci., 57, 476 (1976).

6) Wagstaff, I., and C.E. Chaffey, J. Colloid Interface
Sci., 59, 53 (1977).

7) Chaffey, C.E., and I. Wagstaff, J. Colloid Interface Sci., 59, 63 (1977).

8) Krieger, I.M., Trans. Soc. Rheol., 7, 101 (1963).

9) Krieger, I.M., Adv. Colloid Interface Sci., 3, 111 (1972).

10) Willey, S.J., and C.W. Macosko, J. Rheol., 22, 525 (1978).

11）大坪泰文, 梅屋 薫, 日本レオロジー学会誌, 9, 111 (1981).

12) Otsubo, Y., and K. Umeya, J. Rheol., 28, 95 (1984).

13) Guth, E., and O. Gold, Phys. Rev., 53, 322 (1938).

14) Doroszkowski, A., and R. Lambourne, J. Colloid Interface Sci., 26, 214 (1968).

15) Iler, R.K., J. Colloid Interface Sci., 37, 364 (1974).

16) Fleer, G.J., L.K. Koopal, and J. Lyklema, Kolloid $Z$. Z. Polym., 250, 689 (1972).

17) Ottewill, R.H., and T. Walker, Kolloid Z. Z. Polym., 227, 108 (1968).

18) Vold, M.J., J. Colloid Sci., 16, 1 (1961).

19) Vincent, B., J. Colloid Interface Sci., 42, 270 (1973).

20）立花太郎, 目黒謙次郎, 北原文雄, 森本哲雄, 渡辺 昌, 古澤邦夫, 妹尾 学, “コロイド化学”, p. 132 (1981) 共 立出版.

21) Matsumoto, T., C. Hitomi, and S. Onogi, Trans. Soc. Rheol., 19, 541 (1975).

22) Nicodemo, L., and L. Nicolais, J. Appl. Polym. Sci., 18, 2809 (1974).

23) Umeya, K., and Y. Otsubo, J. Rheol., 24, 239 (1980).

24) Hoffman, R.L., Trans. Soc. Rheol., 16, 155 (1972).

25) Hoffman, R.L., J. Colloid Interface Sci., 46, 491 (1974). 